\title{
Nanoporous gyroid platinum with high catalytic activity from block copolymer templates via electroless plating
}

\author{
Chung-Fu Cheng ${ }^{1}$, Han-Yu Hsueh ${ }^{2}$, Chih-Huang Lai ${ }^{1}$, Chun-Jern Pan ${ }^{3}$, Bing-Joe Hwang ${ }^{3}$, Chi-Chang $\mathrm{Hu}^{2}$ and \\ Rong-Ming $\mathrm{Ho}^{2}$
}

\begin{abstract}
Nanoporous platinum (Pt) with a gyroid nanostructure was fabricated using a nanoporous polymer with gyroid nanochannels as a template. The nanoporous polymer template was obtained from the self-assembly of the degradable block copolymer, polystyrene- $b$-poly(L-lactide) (PS-PLLA), followed by the hydrolysis of the PLLA blocks. Templated electroless plating can be conducted under ambient conditions to create a precisely controlled Pt gyroid nanostructure with high crystallinity in a PS matrix. After removal of the PS matrix, the well-interconnected nanoporous gyroid Pt can be successfully fabricated. Compared with commercially available catalysts, the nanoporous Pt possesses superior macroscopic stability and peak specific activity, benefiting from the well-defined network structure with robust texture and the growth of the low-index crystalline facets of Pt. NPG Asia Materials (2015) 7, e170; doi:10.1038/am.2015.13; published online 3 April 2015
\end{abstract}

\section{INTRODUCTION}

Platinum (Pt) materials with a well-defined nanostructure have attracted substantial scientific attention because of their fascinating properties for a variety of applications, including highly active catalysts, ${ }^{1-3}$ actuators, ${ }^{4,5}$ nanodevices, ${ }^{6,7}$ electrodes ${ }^{8-11}$ and sensors. ${ }^{12-14} \mathrm{Pt}$ is the most promising electrochemical catalyst to facilitate the reactions at the cathode (oxygen reduction reaction) and the anode (methanol oxidation reaction) of a direct methanol fuel cell. Most Pt catalysts consist of Pt nanoparticles supported by carbon, providing a high electrochemically active surface area (ECSA). The major problems for the practical applications of the carbon-supported Pt nanoparticles are carbon corrosion and aggregation, as well as the Ostwald ripening of the Pt nanoparticle during the electrochemical reaction of the fuel cell. ${ }^{15}$ To alleviate the problem and prolong the durability performance, the fabrication of nanoporous $\mathrm{Pt}$ is required. Various nanoporous Pt materials composed of nanowire networks, ${ }^{16-19}$ nanotubes, ${ }^{20,21}$ nanodendrites ${ }^{22-24}$ and hollowed nanocrystals ${ }^{25-27}$ have been fabricated for this purpose. Among them, nanoporous Pt materials with three-dimensional (3D) textures are of significant interest because of the well-defined and well-interconnected networks that provide the required robustness to simultaneously prolong the durability lifetime and increase the residence time of the reactant molecules on the metal surface owing to the confinement effect ${ }^{28}$ of the enhancement of the electrochemical reactions. Xia et al. ${ }^{23}$ developed a novel method for the fabrication of nanoporous $\mathrm{Pt}$ using a truncated Pd seed to grow nanodendrites through epitaxial overgrowth of the Pt branches. Recently, Yang et al. ${ }^{25}$ used presynthesized Pt-based 3D nanoparticles to create highly active 3D nanoframes under a spontaneous evolution process in oleylamine ligands. Another straightforward route for the fabrication of nanoporous Pt is to deposit the desired Pt-base materials into templates with defined nanochannels through templated syntheses using mesoporous silica (MCM materials) $)^{29-31}$ or polycarbonate as templates. ${ }^{32,33}$

Over recent decades, block copolymers (BCPs) have been extensively investigated because of their ability to self-assemble into one-, two- or 3D periodic nanostructures, according to their compositions and molecular weights. ${ }^{34,35}$ Moreover, exploiting the degradable character of BCPs, nanoporous polymer materials can be fabricated by the removal of the components in BCPs through ozonolysis, ${ }^{36}$ UV degradation ${ }^{37}$ and reactive ion etching. ${ }^{38}$ Additionally, polylactidecontaining BCPs (such as polystyrene-b-poly(D,L-lactide) and polystyrene- $b$-poly(L-lactide) (PS-PLLA)) are supremely suited for the fabrication of nanoporous polymer materials because of the unstable characteristic of the ester group, which can be easily decomposed in a basic aqueous solution. ${ }^{39-41}$ Among all of the nanostructures resulting from BCP self-assembly, the gyroid is one of the most appealing morphologies for practical applications because of its unique nanostructure, comprising a matrix and two continuous but independent networks in $3 \mathrm{D}$ space. ${ }^{42-44}$ After selective degeneration of one of the constituted blocks, the gyroid nanostructure can be exploited to fully create interconnected nanochannels. Because of the high porosity and large surface area, nanoporous polymer materials can be used as templates for templated synthesis. By exploiting the templating process (that is, nanoreactor concept), certain reactions, such as electroless plating, ${ }^{45-47}$ electrochemical deposition ${ }^{48-50}$ and the sol-gel process, ${ }^{51,52}$ can be performed within the BCP templates for the manufacture of nanohybrids because of the freestanding characteristic of the gyroid networks. After removal of the template,

${ }^{1}$ Department of Materials Science and Engineering, National Tsing Hua University, Hsinchu, Taiwan, R.O.C.; ${ }^{2}$ Department of Chemical Engineering, National Tsing Hua University, Hsinchu, Taiwan, R.O.C. and ${ }^{3}$ Department of Chemical Engineering, National Taiwan University of Science and Technology, Hsinchu, Taiwan, R.O.C. Correspondence: Professor R-M Ho, Department of Chemical Engineering, National Tsing Hua University, 101, Section 2, Kuang Fu Road, Hsinchu, Taiwan 30013, R.O.C. E-mail: rmho@mx.nthu.edu.tw

Received 4 November 2014; revised 7 January 2015; accepted 8 January 2015 
nanoporous gyroid materials can be fabricated with a well-defined texture, which is promising for applications such as ceramic membranes, ${ }^{53-55}$ hybrid solar cells, ${ }^{45}$ membrane reactors ${ }^{56,57}$ and low refractive index materials. $.11,52$

In this study, we propose a new approach for the fabrication of nanoporous Pt with a well-defined texture (that is, gyroid-forming nanostructure) using hydrolyzed PS-PLLA (that is, nanoporous PS) as a template for the electroless plating of Pt. A modified electroless plating of Pt is performed to fabricate well-ordered PS/Pt nanohybrids. After removal of the template, nanoporous gyroid Pt can be obtained. In contrast to electrochemical deposition, the process of electroless plating (that is, chemical deposition) does not require any electric current to pass through the solution to form a deposit because the electroless plating is performed and then followed by the nucleation and growth mechanism. Accordingly, no conductive substrates are required during the deposition process of the metallic materials. Additionally, the method is comprehensive because there are many available procedures for the deposition of various metals using electroless plating. However, it is possible to encounter a blocking problem for the growth of Pt from the templated electroless plate. In contrast to the templated synthesis using MCM materials as templates, the blocking problem can be alleviated in the synthesis of Pt using nanoporous PS as a template owing to its larger pore size. Therefore, with the dedicated control of the deposition process of Pt via the modified electroless plating, well-ordered nanoporous $\mathrm{Pt}$ can be successfully fabricated. Because of the high porosity and high specific surface area with an open-cell characteristic, the nanoporous gyroid $\mathrm{Pt}$ is an excellent catalyst to facilitate electrochemical reactions, especially for use in a direct methanol fuel cell. Compared with commercially available catalysts (PtB (Aldrich, fuel cell grade)) and $\mathrm{Pt} / \mathrm{C}(20 \mathrm{wt} \% \mathrm{Pt}$ on Vulcan XC-72, E-TEK), the nanoporous gyroid Pt possesses superior macroscopic stability and peak specific activity, benefiting from the well-defined network structure with robust texture and the growth of the low-index crystalline facets of Pt.

\section{EXPERIMENTAL PROCEDURES}

\section{Synthesis of PS-PLLA}

The PS-PLLA was prepared by a sequential living polymerization using a double-headed initiator. Detailed synthetic routes of the PS-PLLA sample have been described in our previously published results. ${ }^{58,59}$ The number-average molecular weight and the molecular weight distribution (that is, polydispersity index) of the PS were determined by gel permeation chromatography (GPC). The polydispersity index of PS-PLLA was determined by GPC and the numbers of L-LA repeating units versus styrene repeating units were determined by ${ }^{1} \mathrm{H}$ nuclear magnetic resonance analysis. The number-average molecular weights of the PS, the PLLA and the polydispersity index of the PS-PLLA are $34000 \mathrm{~g} \mathrm{~mol}^{-1}, 27000 \mathrm{~g} \mathrm{~mol}^{-1}$ and 1.21 , respectively. The volume fraction of PLLA, $f_{P L L A}{ }^{v}$, is calculated as 0.37 by assuming that the densities of PS and PLLA are 1.02 and $1.248 \mathrm{~g} \mathrm{~cm}^{-3}$, respectively.

\section{Sample preparation}

Bulk samples of PS-PLLA were prepared by solution casting from a dichloromethane $\left(\mathrm{CH}_{2} \mathrm{Cl}_{2}\right)$ solution (10 wt \% of PS-PLLA with PLLA volume fraction, $\left.f_{P L L A}{ }^{v}=0.37\right)$ at room temperature for 2 weeks and then dried in a vacuum oven at $65^{\circ} \mathrm{C}$ for 3 days. The dry samples were heated to the maximum annealing temperature, $T_{\max }=175^{\circ} \mathrm{C}$, for 3 min to eliminate the PLLA crystalline residues that were formed during the preparation procedure. After quenching from the microphase-separated ordered melt at $175^{\circ} \mathrm{C}$, the samples were prepared for the small-angle X-ray scattering (SAXS) experiments.
Then, the PLLA blocks of the PS-PLLA bulk samples were removed by hydrolysis using a $0.5 \mathrm{~m}$ basic solution that was prepared by dissolving $2 \mathrm{~g}$ sodium hydroxide in a 40/60 (by volume) solution of methanol/ water. After 3 days of hydrolysis, the hydrolyzed samples were rinsed using a mixture of DI water and methanol and were then used as templates for the subsequent seed growth approach.

\section{Nucleation and growth approach}

The nanoporous PS templates with interconnected twisting air networks were soaked in a seeding aqueous solution mixed with methanol $(12 \mathrm{ml})$ and $\mathrm{H}_{2} \mathrm{PtCl}_{6}(0.01-0.02 \mathrm{~g})$ with stirring at room temperature for several hours. After washing gently with a methanol/ $\mathrm{H}_{2} \mathrm{O}$ solution to remove redundant $\mathrm{Pt}$ ions covering the sample surfaces, the pore-filled samples were immersed into a hydrazinium hydroxide $(85 \%, 4 \mathrm{ml})$ methanol solution for the nucleation of Pt. The diameter of the Pt nuclei is approximately $25-30 \mathrm{~nm}$. By controlling the concentration of the Pt ions, the nucleation density of Pt can be well defined. With the control of sufficiently low Pt ion concentrations, a suitable amount of Pt nuclei within the nanochannels of the template can be formed. Subsequently, a fresh growth aqueous solution consisting of $\mathrm{H}_{2} \mathrm{PtCl}_{6}(0.03 \mathrm{~g})$, ascorbic acid $(1 \mathrm{M}, 1 \mathrm{ml})$ and methanol $(12 \mathrm{ml})$ was prepared, and then the pre-treated templates with a low content of Pt nuclei were immersed into the prepared solution. Accordingly, the Pt ions were reduced to Pt clusters arising from the pre-formed Pt nuclei to gradually develop within the nanochannels through the growth process and eventually forming the PS/Pt nanohybrids with a preserved gyroid texture.

\section{Degeneration for the PS template}

To produce the nanostructured Pt materials, the PS template of the PS/Pt nanohybrids was degraded by exposure to UV. The degradation was performed under atmospheric conditions for $24 \mathrm{~h}$ using a UV source. The intensity of the UV source was tuned for the efficient degradation of the PS matrix with a wavelength of $254 \mathrm{~nm}$ and an intensity of $3 \mathrm{~mW} \mathrm{~cm}^{-2}$. Consequently, the nanostructured $\mathrm{Pt}$ materials were easily obtained.

\section{Microscopy (FESEM)}

FESEM observations were performed on a JEOL JSM-6700F (JEOL, Peabody, MA, USA) using accelerating voltages of $1.5-3 \mathrm{keV}$. Prior to the observations, the samples were sputter-coated with $2-3 \mathrm{~nm}$ of $\mathrm{Pt}$ to avoid the charge effect (the Pt coating thickness was estimated from a calculated deposition rate and experimental deposition time).

\section{Small-angle X-ray scattering (SAXS)}

SAXS experiments were conducted at the synchrotron X-ray beamline X27C at the National Synchrotron Radiation Research Center (NSRRC) in Hsinchu. The wavelength of the X-ray beam was $0.155 \mathrm{~nm}$. A MAR CCD X-ray detector (Rayonix, L.L.C., Evanston, IL, USA) was used to collect the two-dimensional (2D) SAXS patterns. A one-dimensional (1D) linear profile was obtained by integration of the $2 \mathrm{D}$ pattern. The scattering angle of the SAXS pattern was calibrated using silver behenate, with the first-order scattering vector $q\left(q=4 \lambda^{-1} \sin \theta\right.$, where $2 \theta$ is the scattering angle $)$ of $1.076 \mathrm{~nm}^{-1}$.

\section{Wide-angle $\mathrm{X}$-ray scattering}

To further confirm the structure of the ordered nanoporous $\mathrm{Pt}$, we collected the powder of nanoporous $\mathrm{Pt}$ and performed an X-ray diffraction experiment. The crystal structure of the as-prepared product was characterized by X-ray diffraction using a Rigaku Dmax 2200 X-ray diffractometer (The Woodlands, TX, USA) with Cu KR 
radiation $(\lambda=0.1542 \mathrm{~nm})$. The scanning $2 \theta$ angle ranged between $20^{\circ}$ and $120^{\circ}$ with a step scanning of $1^{\circ}$ for $1 \mathrm{~s}$.

\section{Electrochemical experiments}

Electrode preparation. Electrochemical measurements were performed using a glassy carbon rotating disk electrode (Pine Research Instrumentation, Grove City, PA, USA) connected to a PARSTAT 283 potentiostat (Princeton Applied Research, Oak Ridge, TN, USA). A leak-free $\mathrm{AgCl} / \mathrm{Ag} / \mathrm{KCl}(3 \mathrm{M}$ ) electrode (Warner Instrument, Hamden, CT, USA) was used as the reference. All of the potentials were converted to values with reference to a normal hydrogen electrode. The counter electrode was a Pt mesh attached to a Pt wire. The electrolyte was $0.1 \mathrm{~m}$ perchloric acid diluted from $70 \%$ (Baker, ACS Reagent grade, Center Valley, PA, USA) using Millipore ultrapure water (Billerica, MA, USA).

Cyclic voltammetry studies. For the $\mathrm{Pt} / \mathrm{C}$ catalyst $(20 \mathrm{wt} \% 3.2-\mathrm{nm} \mathrm{Pt}$ nanoparticles on a Vulcan XC-72 carbon support; E-TEK (Somerset, NJ, USA)), the sample was diluted to $3.3 \mathrm{mg} \mathrm{ml}^{-1}$, and then $0.5 \mu \mathrm{l}$ of the dispersion was transferred onto the rotating disk electrode. Therefore, the loading amount of metal for the $\mathrm{Pt} / \mathrm{C}$ catalyst was $1.65 \mu \mathrm{g}$ (that is, $10.57 \mu \mathrm{g} \mathrm{cm}{ }^{-2}$ based on the geometric electrode area). For the nanoporous gyroid Pt and Pt black (Aldrich (St Louis, $\mathrm{MO}$, USA), fuel cell grade), the working electrode was prepared using the same procedure, except that the loading amount of the metal was $3.3 \mu \mathrm{g}$ (that is, $21.5 \mu \mathrm{g} \mathrm{cm}^{-2}$ based on the geometric electrode area). Upon drying in air for $2 \mathrm{~h}$, the electrode was covered with $15 \mu \mathrm{l}$ of $0.05 \mathrm{wt} \%$ Nafion solution. After evaporation of water, the electrode was placed under vacuum for $30 \mathrm{~min}$ before the measurement.

Electrochemically active surface area (ECSA). Cyclic voltammetry $(\mathrm{CV})$ measurements were performed in $0.1 \mathrm{M} \mathrm{HClO} 4$ solutions under a flow of N2 (Airgas, ultrahigh purity) at a sweep rate of $50 \mathrm{mV} \mathrm{s}^{-\mathrm{V}}$. The ECSA was estimated by measuring the charge associated with the $\mathrm{H}_{\text {upd }}$ adsorption $\left(Q_{H}\right)$ between 0 and $0.37 \mathrm{~V}$ and by assuming 210 $\mu \mathrm{Cm}^{-2}$ for the adsorption of a monolayer of hydrogen on a $\mathrm{Pt}$ surface $\left(q_{H}\right)$. Subsequently, the specific ECSA was calculated based on the following relationship:

$$
\text { Specific ECSA }=\frac{Q_{H}}{m q_{H}}
$$

where $Q_{H}$ is the charge for $\mathrm{H}_{\text {upd }}$ adsorption, $m$ is the loading amount of metal, and $q_{H}$ is the charge required for monolayer adsorption of hydrogen on a Pt surface.

Methanol oxidation reaction. In the methanol oxidation reaction studies, all of the prepared samples were transferred to a glassy carbon substrate (geometric area of $1 \mathrm{~cm}^{2}$ ). The loading density for nanoporous gyroid $\mathrm{Pt}, \mathrm{PtB}$ and $\mathrm{Pt} / \mathrm{C}$ was modified by approximately 0.06 $\mathrm{mg} \mathrm{cm}{ }^{-2}, 0.25 \mathrm{mg} \mathrm{cm}^{-2}$ and $0.26 \mathrm{mg} \mathrm{cm}^{-2}$, respectively. The CV curves were recorded between 0 and $1.3 \mathrm{~V}$ versus normal hydrogen

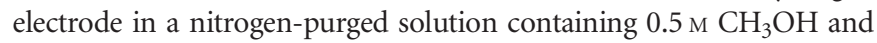
$0.5 \mathrm{M} \mathrm{H}_{2} \mathrm{SO}_{4}$ at the scan rate of approximately $50 \mathrm{mV} \mathrm{s}^{-1}$.

\section{RESULTS AND DISCUSSION}

\section{Electroless plating of Pt from the BCP template}

Figure 1a shows the schematic illustration of this method for the fabrication of PS/Pt gyroid nanohybrids. A PS-PLLA was synthesized with a molecular weight of $61000 \mathrm{~g} \mathrm{~mol}^{-1}$ and a PLLA volume fraction of $37 \%$. A double gyroid phase consisting of co-continuous PLLA networks in a PS matrix can be formed after solution casting of the synthesized PS-PLLA followed by quenching from a microphaseseparated melt. The 1D SAXS profile shown in Figure 2a confirms the double gyroid phase from the self-assembly of the PS-PLLA in which reflections are found at the relative $q$ values of $\sqrt{ } 6: \sqrt{ } 8: \sqrt{ } 14: \sqrt{ } 16: \sqrt{ } 32$, indicating the formation of the gyroid phase. The inter-domain spacing of the $(211)_{\text {gyroid }}\left(d_{(211) \mathrm{G}}\right)$ was determined as approximately $50.8 \mathrm{~nm}$ from the primary reflection, suggesting a cubic unit cell of $118.8 \mathrm{~nm}$ for the formation of the gyroid phase. Figure $2 \mathrm{~b}$ displays the 1D SAXS profile of the PS-PLLA after hydrolysis; the reflections at the relative $q$ values remain unchanged compared with Figure 2a, reflecting the preservation of the gyroid phase after hydrolytic treatment,

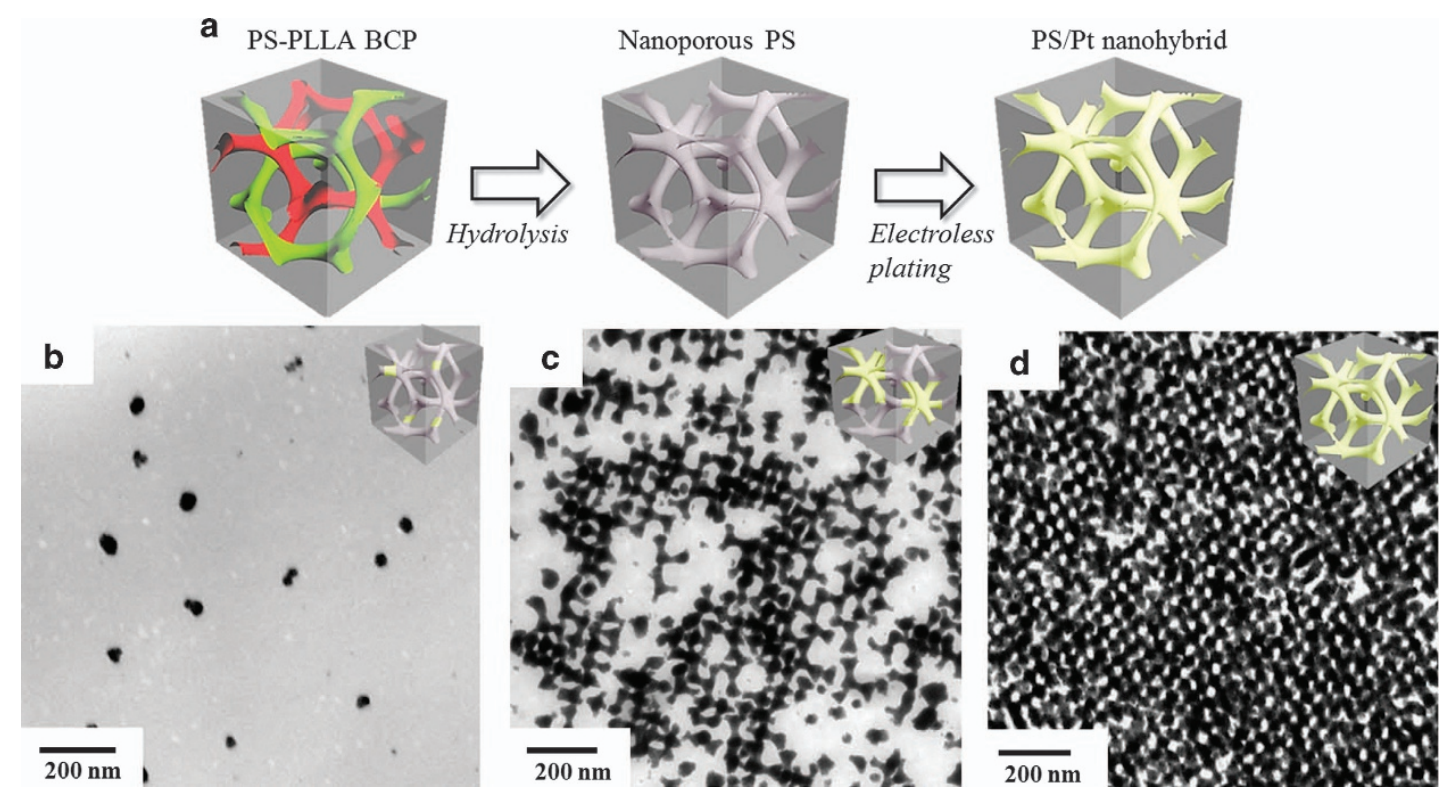

Figure 1 (a) Schematic illustration for the fabrication of the PS/Pt gyroid nanohybrids using a BCP template from the hydrolysis of PS-PLLA for electroless plating. Transmission electron micrographs of the nanohybrids after seeding (b), followed by 2-day growth (c) and 5-day growth (d). The inset shows the corresponding illustration. 


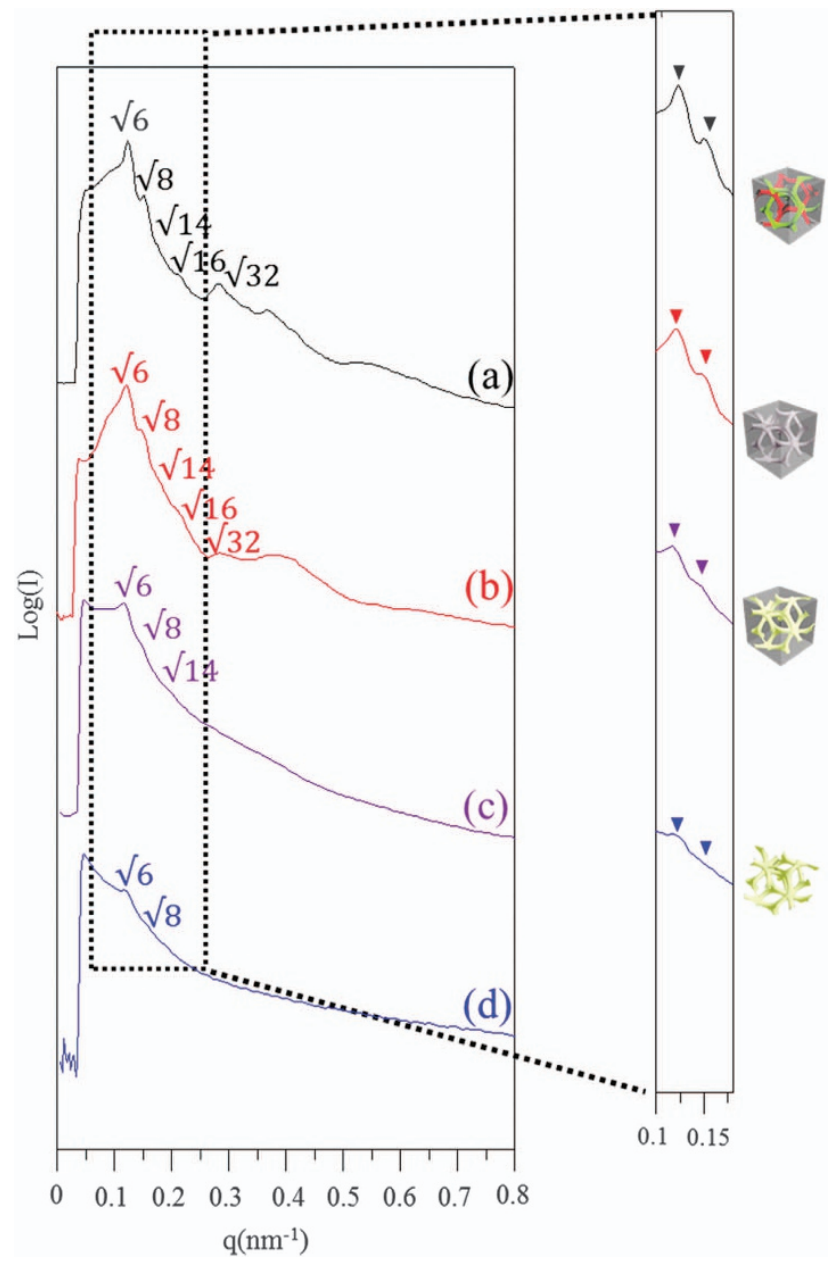

Figure 2 One-dimensional SAXS profiles of (a) PS-PLLA after quenching from the microphase-separated melt; (b) nanoporous PS template after removal of the PLLA blocks in PS-PLLA by hydrolysis; (c) PS/Pt gyroid nanohybrids; (d) nanoporous gyroid Pt. The inset shows the enlarged region of the $q$ value from 0.1 to $0.18 \mathrm{~nm}^{-1}$. The triangles in the inset mark the scattering peaks of $\sqrt{ } 6$ and $\sqrt{ } 8$ for the gyroid nanostructure.

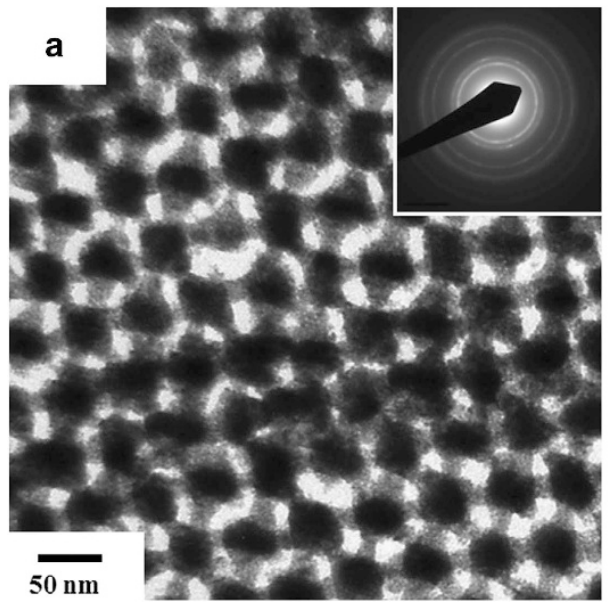

suggesting that the PLLA networks can be selectively removed. Supplementary Figure S1 shows the pore size distribution of the nanoporous PS templates after the hydrolysis of PLLA in PS-PLLA; the average pore size was determined to be approximately $20.4 \mathrm{~nm}$ (see SI for details). Therefore, a PS matrix with well-defined, bicontinuous nanochannels can be fabricated and employed as a template for subsequent electroless plating of Pt.

To create the initial stage for the seeding of Pt from electroless plating, the PS template was soaked in a $\mathrm{Pt}^{4+}\left(\mathrm{H}_{2} \mathrm{PtCl}_{4}\right)$ solution mixed with methanol to enhance the wetting tendency of the aqueous solution for pore filling of the PS template through capillary force. The nanoporous template was then immersed into hydrazinium hydroxide $\left(\mathrm{N}_{2} \mathrm{H}_{5} \mathrm{OH}\right)$ (a strong reducing agent for Pt ions) at room temperature to rapidly reduced the $\mathrm{Pt}$ ions into nanoparticles inside of the nanochannels (Figure 1b). The nanoparticle size is approximately $20 \mathrm{~nm}$ in diameter, as measured from the transmission electron micrographs, equivalent to the diameter of the nanochannel of the template. The nucleation density was calculated from the results of the transmission electron microscopy microtone section with a thickness of $50 \mathrm{~nm}$ and estimated as $6 \times 10^{13}$ per cubic centimeter $\left(\mathrm{cm}^{3}\right)$. For the subsequent growth process using the nanoparticle as the nuclei site for the self-catalytic reaction, a relatively weak reducing agent (that is, ascorbic acid) was used. Figure 1c shows the textures of the Pt after a 2-day growth from the reduced nanoparticles in which multibranched Pt can be clearly recognized, indicating successful templating of the gyroid texture from the nucleation and growth processes. After a 5-day growth, as shown in Figure 1d, well-ordered gyroid Pt nanostructures can be successfully fabricated in the PS matrix, reflecting the successful development of gyroid Pt from the branched Pt. Note that the use of a highly active reducing agent may cause blocking of the nanochannels (see Supplementary Figure S2). Therefore, control of the reduction rate is required for the fabrication of a well-interconnected network Pt inside of the PS templates, which can be adjusted and modified by the type and concentration of the reducing agent and the precursor for the nucleation and growth process. Figure 3 shows the [111] and [100] transmission electron microscopy projections of the PS/Pt nanohybrids, suggesting the formation of double gyroid Pt with well-interconnected networks in the PS template after electroless plating. Figure 2c shows the corresponding 1D SAXS profile of the nanohybrids. On the basis of the characteristic reflections for the nanohybrids at the relative $q$

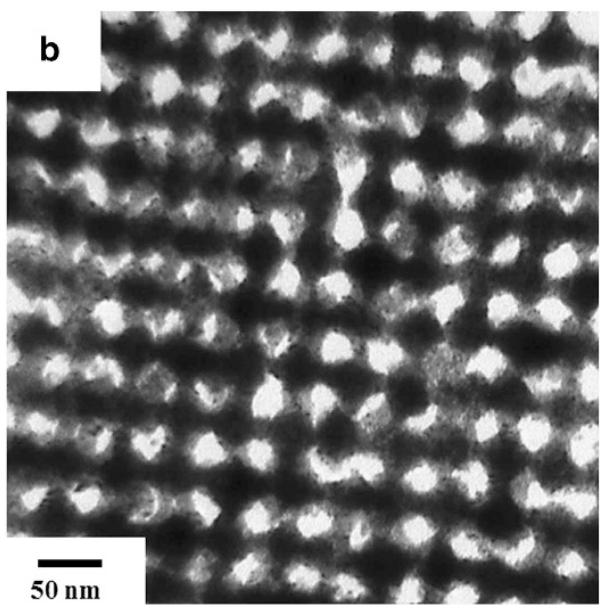

Figure 3 Transmission electron micrographs of the PS/Pt gyroid nanohybrids with projections along (a) [111]; (b) [100]. The inset shows the corresponding selected area electron diffraction pattern. 
values of $\sqrt{ } 6: \sqrt{ } 8: \sqrt{ } 14$, the gyroid-forming PS/Pt nanohybrids can be identified macroscopically. The weak reflection contrast in the high $q$ region is due to the stronger diffraction from the $\mathrm{Pt}$ and the effect from the form factor of $\mathrm{Pt}^{60}$

\section{Nanoporous gyroid Pt}

After removal of the PS by UV degradation, a well-ordered network morphology can be found, as shown in Figure 4a. Figure 4b shows the FESEM image with unique gyroid textures, indicating that $\mathrm{Pt}$ with well-defined networks and precise control of pore geometry can be prepared. The structure of the nanoporous gyroid Pt can be further identified by SAXS (Figure 2d); the reflections at the relative $q$ values of $\sqrt{ } 6: \sqrt{ } 8$ can be found, suggesting the successful preservation of the gyroid structure after removal of the PS, although the reflections are barely recognizable compared with those in Figure 2c. In addition to the described effects of the Pt on scattering, the smearing of the reflections might be attributed to the deformation and/or the collapse of the Pt network after removal of the template. To examine the crystalline characteristics of the nanoporous gyroid Pt, selected area electron diffraction and wide-angle X-ray diffraction were conducted. The inset of Figure 3a displays the selected area electron diffraction pattern of the PS/Pt nanohybrids. All of the rings can be indexed with the face-centered cubic Pt polycrystals (see Supplementary Figure S3 for details). The wide-angle X-ray diffraction results of the nanoporous gyroid Pt (Figure 4c) are in agreement with the selected area electron diffraction results. All of the diffractions can be indexed as facecentered cubic Pt with the lattice constant $\mathrm{a}=3.920 \AA$, JCPDS card no. 04-0802, corresponding to the reflections of (111), (210), (220), (311) and (220). Furthermore, X-ray photoelectron spectroscopy was used to examine the elemental composition of the nanoporous gyroid Pt. As evidenced by X-ray photoelectron spectroscopy (Supplementary Figure S4), the results show that the C1s peak for the nanoporous Pt is barely detectable compared with that for the PS/Pt nanohybrids, indicating that PS is almost completely removed from the nanoporous gyroid Pt. Moreover, the characteristic peaks of crystalline Pt (binding energy $=70,314,331$ and $519 \mathrm{eV}$ ) remain after the UV exposure, reflecting that the fabricated nanoporous Pt retains its pure metallic character without any impurities. The peak corresponding to O1s $(531 \mathrm{eV})$ can be observed; we speculate that the peak is attributed to the exposure of the metal surface to the air. There is no X-ray photoelectron spectroscopy peak relevant to metal oxides, indicating that the amount of $\mathrm{PtO}$ species should be insignificant. Therefore, UV can be used to completely degrade the PS template to yield the nanoporous Pt in its intrinsic form for catalytic applications. Note that metallic materials with fine grains and high purity would exhibit better mechanical strength and catalytic efficiency compared with amorphous materials.

\section{Electrochemical properties of nanoporous $\mathrm{Pt}$}

Pt with well-defined nanostructure has been demonstrated to provide superior catalytic activity for electrochemical reactions; for example, $\mathrm{Pt}$ with a $1 \mathrm{D}$ nanorod structure can be applied to the catalytic electrode in a direct methanol fuel cell by conducting the oxygen reduction reaction (cathode reaction) and the methanol oxidation reaction (anode reaction). ${ }^{31}$ For the fabricated nanoporous gyroid $\mathrm{Pt}$, the electronic continuity was probed using cyclic voltammetry. Cyclic
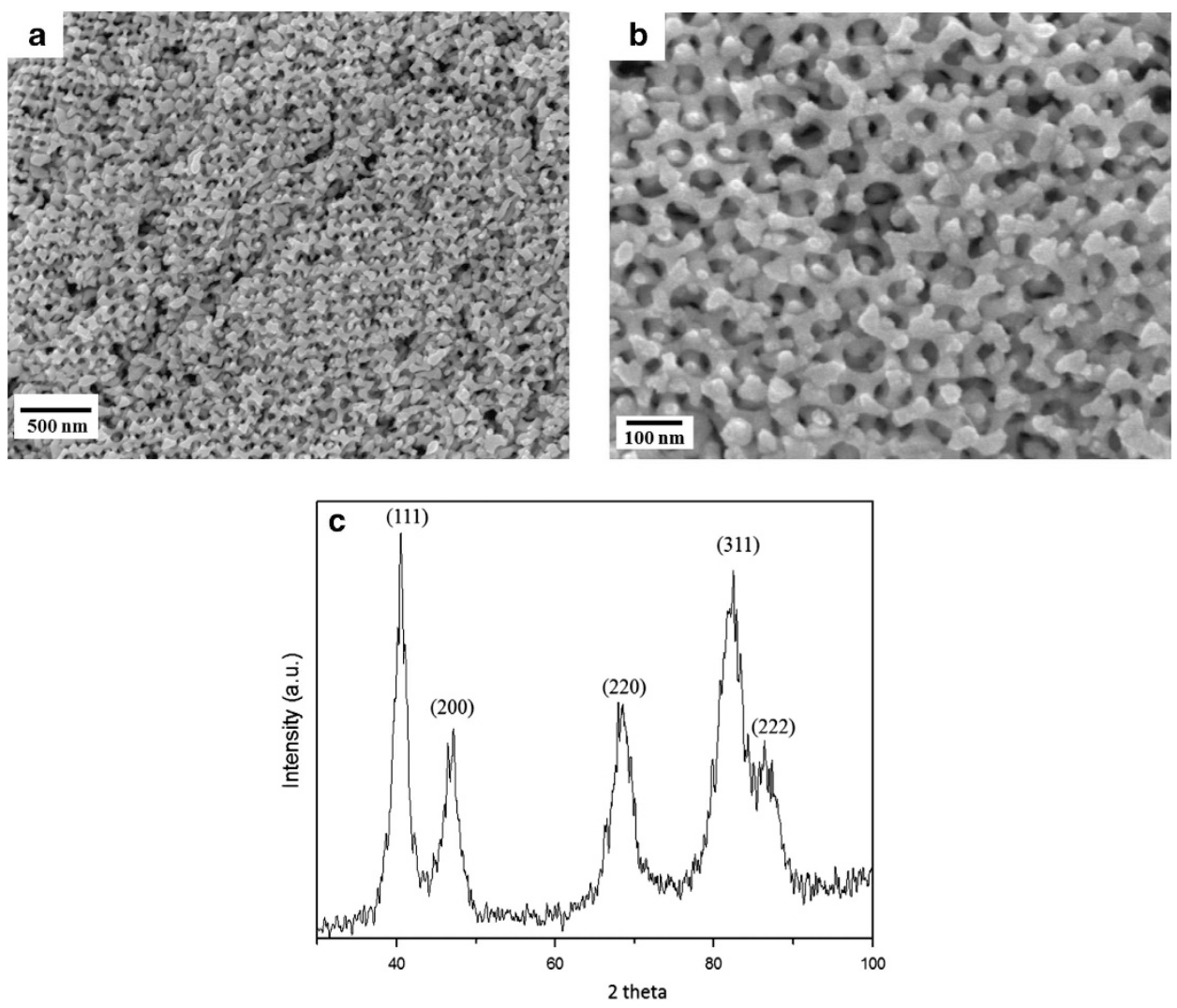

Figure 4 ( $\mathbf{a}$ and $\mathbf{b}$ ) FESEM micrographs of the nanoporous gyroid Pt from the PS/Pt gyroid nanohybrids after removal of the PS templates by UV degradation; (c) One-dimensional X-ray diffraction profile of the nanoporous gyroid Pt. 
a

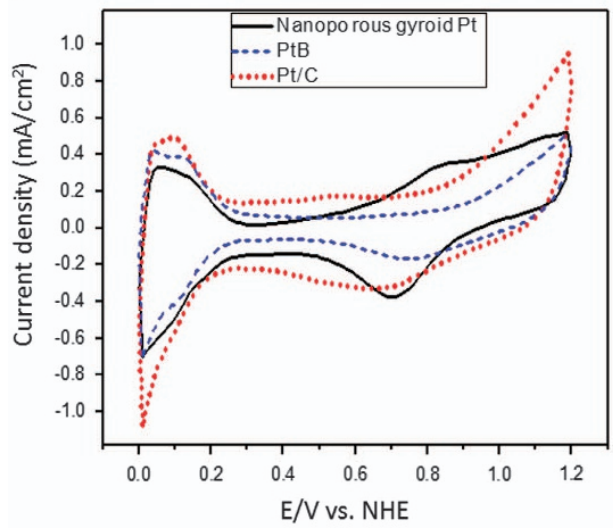

b

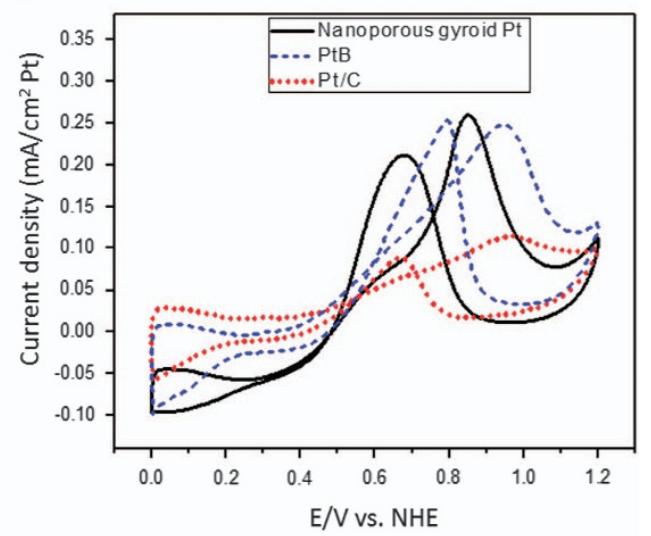

C

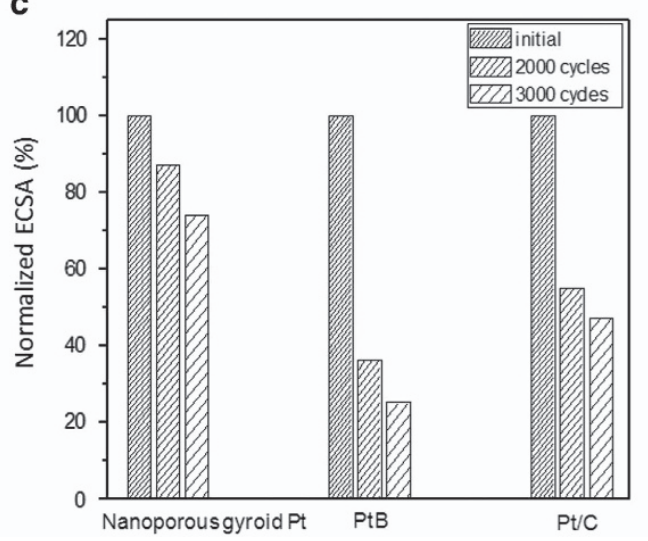

Figure 5 (a) Cyclic voltammograms of gyroid Pt, PtB and Pt/C in $\mathrm{N}_{2}$-purged $0.1 \mathrm{M} \mathrm{HClO}_{4}$; (b) Cyclic voltammograms of nanoporous gyroid Pt, PtB and $\mathrm{Pt} / \mathrm{C}$ in $\mathrm{N}_{2}$-purged $0.5 \mathrm{M} \mathrm{H}_{2} \mathrm{SO}_{4}+0.5 \mathrm{M}$ methanol solution; (c) Comparison of the normalized ECSA of gyroid Pt, PtB and Pt/C after 0, 2000 and $3000 \mathrm{CV}$ cycles in a $0.1 \mathrm{M} \mathrm{HClO}_{4}$ solution.

voltammograms of the nanoporous gyroid Pt were recorded in a nitrogen-purged $0.1 \mathrm{M} \mathrm{HClO}_{4}$ solution at the sweeping rate of 50 $\mathrm{mV} \mathrm{s}^{-1}$ between 0 and $1.2 \mathrm{~V}$ relative to the normal hydrogen electrode. Figure 5a shows the electrocatalytic properties of the nanoporous gyroid $\mathrm{Pt}$ compared with commercially available $\mathrm{Pt}$ nanoparticle catalysts, including $\mathrm{PtB}$ and $\mathrm{Pt} / \mathrm{C}$. The $\mathrm{CV}$ curves exhibit two distinctive potential regions associated with the adsorption/ desorption of the underpotential deposition of hydrogen $\left(\mathrm{H}_{\text {upd }}\right)$ between 0 and $0.37 \mathrm{~V}$ in the $\mathrm{CV}$ curves and the formation of adsorbed hydroxyl species $\left(\mathrm{OH}_{\mathrm{ad}}\right)$ beyond $0.6 \mathrm{~V}$ (see below for details). The ECSA is a quantitative electrochemical property that is sensitively dependent on the size and shape as well as the crystalline interface between the nanostructured $\mathrm{Pt}$ and the working environment. The ECSA is estimated using the charge collected in this $\mathrm{H}_{\text {upd }}$ region between 0 and $0.37 \mathrm{~V}$, based on the hydrogen underpotential deposition charge, $\mathrm{Q}_{\mathrm{H}, \mathrm{d}}$, after double-layer correction and the assumed value of $210 \mu \mathrm{C} \mathrm{cm}^{-2}$ for the desorption of a hydrogen monolayer. On the basis of the CV curves (Figure 5a), the ECSA values are calculated as approximately $15.6,22.2$ and $72.8 \mathrm{~m}^{2} \mathrm{~g}^{-1}$ for nanoporous gyroid $\mathrm{Pt}, \mathrm{PtB}$ and $\mathrm{Pt} / \mathrm{C}$, respectively. We speculate that the relatively lower ECSA for the nanoporous gyroid Pt catalyst is attributed to its larger Pt size $(\sim 20 \mathrm{~nm})$ compared with that of the Pt nanoparticles $(\sim 3 \mathrm{~nm})$ in commercially available catalysts.

Figure $5 \mathrm{~b}$ displays the cyclic voltammetry curves of the methanol oxidation reaction catalyzed by the nanoporous gyroid Pt. The entire process was conducted at room temperature in a $0.5 \mathrm{M} \mathrm{H}_{2} \mathrm{SO}_{4}$ solution containing $0.5 \mathrm{~m}$ methanol. The curves were normalized by experimentally determined ECSA. Two obvious anodic peaks, which is a typical feature of the methanol oxidation reaction, can be clearly identified during the positive sweep. The onset potential $(0.63 \mathrm{~V})$ of the nanoporous gyroid $\mathrm{Pt}$ was determined for the electrocatalytic oxidation of methanol compared with PtB $(0.76 \mathrm{~V})$ and $\mathrm{Pt} / \mathrm{C}(0.79 \mathrm{~V})$. The lower onset potential of the nanoporous gyroid $\mathrm{Pt}$ results in a negative shift peak potential, indicating that the methanol oxidation catalyzed by gyroid $\mathrm{Pt}$ is substantially easier to trigger. The ratio of the forward anodic peak current density $\left(\mathrm{I}_{\mathrm{f}}\right)$ to the backward peak current density $\left(\mathrm{I}_{\mathrm{b}}\right), \mathrm{I}_{\mathrm{f}} / \mathrm{I}_{\mathrm{b}}$ value, can be used to investigate the tolerance of the catalyst for carbonaceous species. A low $\mathrm{I}_{\mathrm{f}} / \mathrm{I}_{\mathrm{b}}$ value typically indicates poor oxidation of methanol to $\mathrm{CO}_{2}$ during the forward anodic scan and excessive accumulation of residual carbonaceous species on the catalyst surface. The higher $\mathrm{I}_{\mathrm{f}} / \mathrm{I}_{\mathrm{b}}$ value indicates its higher tolerance to the poison. ${ }^{61,62}$ As calculated from the results, the $\mathrm{I}_{\mathrm{f}} / \mathrm{I}_{\mathrm{b}}$ values are 1.22 , 0.96 and 1.26 for the nanoporous gyroid $\mathrm{Pt}, \mathrm{PtB}$ and $\mathrm{Pt} / \mathrm{C}$, respectively. The specific activities of anodic peaks for gyroid $\mathrm{Pt}, \mathrm{PtB}$ and $\mathrm{Pt} / \mathrm{C}$ were then calculated as approximately $0.26,0.24$ and 0.12 $\mathrm{mA} \mathrm{cm}{ }^{-2}$, respectively, demonstrating a better performance in specific activity for nanoporous gyroid $\mathrm{Pt}$ compared with that of the commercially available PtB and Pt/C catalysts. The mass activities of the anodic peaks were determined as approximately 40.8, 87.3 and $48.0 \mathrm{~mA} \mathrm{mg}^{-1}$ for the nanoporous gyroid $\mathrm{Pt}, \mathrm{PtB}$ and $\mathrm{Pt} / \mathrm{C}$, respectively. The specific activity of the nanoporous gyroid $\mathrm{Pt}$ is more than two times higher than that of $\mathrm{Pt} / \mathrm{C}$, whereas the peak mass activity is 
approximately $47 \%$ of $\mathrm{Pt} / \mathrm{C}$. Compared with $\mathrm{PtB}$, the nanoporous gyroid Pt exhibits better performance in specific activity but shows a relatively lower value of mass activity. The relatively better performance of the nanoporous gyroid Pt in the specific activity might be attributed to the appearance of low index crystalline facets near the surface of the nanoporous gyroid Pt in addition to the higher specific surface area for electrochemical reaction. As shown in Supplementary Figure S5, based on the high-resolution transmission electron microscopy results, the presence of the low-index crystalline facets can be identified; we speculate that the growth of the low-index crystalline facets is attributed to the confined growth of the Pt within the nanochannels of the PS template. Note that the low-index crystalline facets of Pt would yield a higher catalytic activity. ${ }^{63}$ Moreover, based on the X-ray absorption near-edge structure spectra at the $\mathrm{Pt}_{\mathrm{L}}$-edge $(11564 \mathrm{eV})$ (Supplementary Figure S6), nanoporous gyroid Pt shows a relatively lower absorption intensity than $\mathrm{PtB}$ and $\mathrm{Pt} / \mathrm{C}$, further demonstrating the stabilization of the $d$ orbital electron due to the lower number of unoccupied $d$-states per Pt atom, resulting in better performance as an electrocatalyst. ${ }^{64}$ Therefore, it is reasonable to have a higher specific activity for the nanoporous gyroid $\mathrm{Pt}$ than $\mathrm{PtB}$ and $\mathrm{Pt} / \mathrm{C}$, whereas the relatively lower value of the mass activity of the nanoporous gyroid $\mathrm{Pt}$ is attributed to the larger characteristic size of the nanoporous gyroid Pt than the commercially available catalysts.

\section{Performance of durability}

Note that the durability of the catalyst materials is a severe problem for practical applications that must be addressed to evaluate their performance. To investigate the durability of the $\mathrm{Pt}$, repeated cycling was conducted in an oxygen-saturated $0.1 \mathrm{M} \mathrm{HClO}_{4}$ solution by applying voltage from 0 to $1.2 \mathrm{~V}$ at the scan rate of $50 \mathrm{mV} \mathrm{s}^{-1}$. The decrease of the ECSA with the number of cycling rounds is depicted in Figure 5c. A significant loss of ECSA can be observed for PtB and Pt/C, whereas the ECSA value of the nanoporous gyroid Pt shows only a slight decrease during the CV measurements. After 2000 cycles, the ECSA is reduced to 64 and $49 \%$ for $\mathrm{PtB}$ and $\mathrm{Pt} / \mathrm{C}$, respectively, in contrast to the $13 \%$ loss in the nanoporous gyroid Pt. After 3000 cycles, the nanoporous gyroid Pt experiences only approximately $26 \%$ loss of ECSA, whereas a significant loss for $\mathrm{PtB}$ and $\mathrm{Pt} / \mathrm{C}$ (75\% loss and 65\% loss, respectively) can be found (see Supplementary Figure S7 for details). Pt with a 3D network structure was demonstrated to significantly enhance the duration performance. We speculate that the enhancement of the duration performance of $\mathrm{Pt}$ is attributed to the well-interconnected network structure that addresses certain problems in the application as electrocatalyst, including particle aggregation and loss of electrical contact, as well as other disadvantages, such as Ostwald ripening.

\section{CONCLUSIONS}

In conclusion, nanoporous PS with gyroid nanochannels can be fabricated from the self-assembly of the degradable BCP, PS-PLLA, followed by the hydrolysis of the PLLA blocks. A modified electroless plating method for templated synthesis using the nanoporous PS as a template was demonstrated to prepare well-ordered PS/Pt nanohybrids with a well-defined network morphology by exploiting the nucleation and growth mechanism during the templating process under ambient conditions. After removal of the PS template, nanoporous gyroid Pt can be fabricated and used for electrochemical catalysis. Benefiting from the well-defined network structure with robust texture and the presence of low-index crystalline facets of $\mathrm{Pt}$, the nanoporous gyroid Pt can be used as an electrochemical catalyst possessing superior macroscopic stability and peak specific activity compared with commercially available catalysts.

\section{CONFLICT OF INTEREST}

The authors declare no conflict of interest.

\section{ACKNOWLEDGEMENTS}

We thank the Ministry of Science and Technology of the Republic of China, Taiwan, for financially supporting this research under Contract No. Grant MOST 103-2633-M-007-001. We also thank the National Synchrotron Radiation Research Center (NSRRC) for its assistance in the Synchrotron SAXS experiments.

1 Tian, N., Zou, Z. Y., Sun, S. G., Ding, Y. \& Wang, Z. L. Synthesis of tetrahexahedral platinum nanocrystaks with high-index facets and high electro-oxidation activity. Science 316, 732-735 (2007).

2 Wang, D., Xin, H. L., Hovden, R., Wang, H., Yu, Y., Muller, D. A., Disalvo, F. J. \& Abruna, H. D. Structurally ordered intermetallic platinum-cobalt core-shell nanoparticles with enhanced activity and stablity as oxygen reduction electrocatalysts. Nature Materials 12, 81-87 (2013)

$3 \mathrm{Yu}$, T., Kim, D. Y., Zhang, H. \& Xia, Y. Platinum concave nanocubes with high-index facets and their enhanced activity for oxygen reduction reaction. Angew. Chem. Int. Ed. 50, 2773-2777 (2011)

4 Weissmuller, J., Viswanath, R. N., Kramer, D., Zimmer, P., Wurschum, R. \& Gleiter, $\mathrm{H}$. Charge-induced reversible strain in a metal. Science 300, 312-315 (2003).

5 Jin, H. J., Wang, X. L., Parida, S., Wang, K., Seo, M. \& Weissmuller, J. Nanoporous Au-Pt Alloys As Large Strain Electrochemical Actuators. Nano Lett. 10, 187-194 (2009).

6 Yang, J. J., Borghetti, J., Murphy, D., Stewart, D. R. \& Williams, R. S. A family of electronically reconfigurable nanodevices. Adv. Mater. 21, 3754-3758 (2009).

7 Stewart, D. R., Ohlberg, D. A. A., Beck, P. A., Chen, Y. \& Williams, R. S. Moleculeindependent electrical switching in Pt-organic monolayer-Ti devices. Nano Lett 4, 133-136 (2004)

8 Michel, M., Taylor, A., Sekol, R., Podsiadlo, P., Ho, P., Kotov, N. \& Thompson, L. High-performance nanostructured membrane electrode assemblies for fuel cells made by layer-by-layer assembly of carbon nanocolloids. Adv. Mater. 19, 3859-3864 (2007).

9 Kim, O. H., Cho, Y. H., Kang, S. H., Park, H. Y., Kim, M., Lim, J. W., Chung, D. Y., Lee, M. J., Choe, H. \& Sung, Y. E. Ordered macroporous platinum electrode and enhanced mass transfer in fuel cells using inverse opal structure. Nat. Commun 4 2473-2482 (2013).

10 Li, L. L., Wu, H. H., Tsai, C. H. \& Diau, E. W. G. Nanofabrication of uniform and stabilizer-free self-assembled platinum monolayers as counter electrodes for dye-sensitized solar cells. NPG Asia Materials 6, 118-124 (2014).

11 Kloke, A., Stetten, F. V., Zengerle, R. \& Kerzenmacher, S. Strategies for the fabrication of porous platinum electrodes. Adv. Mater. 23, 4976-5008 (2011).

12 Pang, C., Lee, G. Y., Kim, T. I., Kim, S. M., Kim, H. N., Ahn, S. H. \& Suh, K. Y. A flexible and highly sensitive strain-gauge sensor. Nature Materials 11, 795-801 (2012)

13 Yang, F., Donavan, K. C., Kung, S. C. \& Penner, R. M. The surface scattering-based detection of hydrogen in air using a platinum nanowire. Nano Lett. 12 , 2924-2930 (2012).

14 Guo, S., Wen, D., Zhai, Y , Dong S. \& Wang E Platinum nanoparticle ensemble-on-graphene hybrid nanosheets: one-pot, rapid synthesis, and used as new electrode material for electrochemical sensing. ACS Nano 4, 3959-3968 (2010).

$15 \mathrm{Yu}, \mathrm{X} . \&$ Ye, S. Recent Advances in activity and durability enhancement of Pt/C catalytic cathode in PEMFC Part I. Physico-chemical and electronic interaction between Pt and carbon support, and activity enhancement of Pt/C catalyst. Journal of Power Sources 172, 133-144 (2007).

16 Wang, D., Luo, H., Kou, R., Gil, M. P., Xiao, S., Golub, V. O., Yang, Z., Brinker, C. J. \& $\mathrm{Lu}, \mathrm{Y}$. A general route to macroscopic hierarchical 3D nanowire networks. Angew. Chem. Int. Ed. 43, 6169-6173 (2004).

17 Sun, S., Jaouen, F. \& Dodelet, J. P. Controlled growth of Pt nanowires on carbon nanospheres and their enhanced performance as electrocatalysts in PEM fuel cells. Adv. Mater. 20, 3900-3904 (2008).

18 Liang, H. W., Cao, X., Zhou, F., Cui, C. H., Zhang, W. J. \& Yu, S. H. A free-standing Pt-nanowire membrane as a highly stable electrocatalyst for the oxygen reduction reaction. Adv. Mater. 23, 1467-1471 (2011).

19 Koenigsmann, C., Zhou, W. P., Adzic, R. R., Sutter, E. \& Wong, S. S. Size-dependent enhancement of electrocatalytic performance in relatively defect-free, processed ultrathin platinum nanowires. Nano. Lett. 10, 2806-2811 (2010).

20 Xu, H., Ding, L. X., Liang, C. L., Tong, Y. X. \& Li, G. R. High-performance polypyrrole functionalized PtPd electrocatalysts based on PtPd/PPy/PtPd three-layered nanotube arrays for the electrooxidation of small organic molecules. NPG Asia Materials 5, 69-78 (2013).

21 Chen, Z., Waje, M., Li, W. \& Yan, Y. Supportless Pt and PtPd nanotubes as electrocatalysts for oxygen-reduction reactions. Angew. Chem. Int. Ed. 46 4060-4063 (2007). 
22 Ma, L., Wang, C., Gong, M., Liao, L., Long, R., Wang, J., Wu, D., Zhong, W., Kim, M. J., Chen, Y., Xie, Y. \& Xiong, Y. Control over the branched structures of platinum nanocrystals for electrocatalytic applications. ACS Nano 11, 9797-9806 (2012).

23 Lim, B., Jiang, M., Camargo, P. H. C., Cho, E. C., Tao, J., Lu, X., Zhu, Y. \& Xia, Y. $\mathrm{Pd}-\mathrm{Pt}$ bimetallic nanodendrites with high activity for oxygen reduction. Science $\mathbf{3 2 4}$ 1302-1305 (2009).

24 Guo, S., Dong, S. \& Wang, E. Three-dimensional Pt-on-Pd bimetallic nanodendrites supported on graphene nanosheet: facile synthesis and used as an advanced nanoelectrocatalyst for methanol oxidation. ACS Nano 4, 547-555 (2010).

25 Chen, C., Kang, Y., Huo, Z., Zhu, Z., Huang, W. Y., Xin, H. L., Snyder, J. D., Li, D., Herron, J. A., Mavrikakis, M., Chi, M., More, K. L., Li, Y., Markovic, N. M., Somorjai, G. A., Yang, P. \& Stamenkovic, V. R. Highly crystalline multimetallic nanoframes with three-dimensional electrocatalytic surfaces. Science 343, 1339-1343 (2014).

26 Liang, H. P., Zhang, H. M., Hu, J. S., Guo, Y. G., Wan, L. J. \& Bai, C. L. Pt hollow nanospheres: facile synthesis and enhanced electrocatalysts. Angew. Chem. Int. Ed. 43, 1540-1543 (2004)

27 Esfahani, H. A., Nemoto, Y., Wang, L. \& Yamauchi, Y. Rational synthesis of Pt spheres with hollow interior and nanosponge shell using particles as template. Chem. Commun. 47, 3885-3887 (2011).

28 Han, J. H., Lee, E., Park, S., Chang, R. \& Chung, T. D. Effect of nanoporous structure on enhanced electrochemical reaction. J. Phys. Chem. C 114, 9546-9553 (2010)

29 Doi, Y., Takai, A., Sakamoto, Y., Terasaki, O., Yamauchi, Y. \& Kuroda, K. Tailored synthesis of mesoporous platinum replicas using double gyroid mesoporous silica (KIT-6) with different pore diameters via vapor infiltration of a reducing agent. Chem. Commun. 46, 6365-6367 (2010).

30 Kibsgaard, J., Gorlin, Y., Chen, Z. \& Jaramillo, T. F. Meso-structured platinum thin films_active and stable electrocatalysts for the oxygen reduction reaction. J. Am. Chem. Soc. 134, 7758-7765 (2012)

31 Wang, H., Jeong, H. Y., Imura, M., Wang, L., Radhakrishnan, L., Fujita, N., Castle, T., Terasaki, O. \& Yamauchi, Y. Shape- and size-controlled synthesis in hard templates sophisticated chemical reduction for mesoporous monocrystalline platinum nanoparticles. J. Am. Chem. Soc. 133, 14526-14529 (2011).

32 Rauber, M., Alber, I., Muller, S., Neumann, R., Picht, O., Roth, C., Schokel, A., Molares, M. E. T. \& Ensinger, W. Highly-ordered supportless three-dimensional nanowire networks with tunable complexity and interwire connectivity for device integration. Nano Lett. 11, 2304-2310 (2011).

$33 \mathrm{Li}$, C., Sato, T. \& Yamauchi, Y. Electrochemical synthesis of one-dimensiona mesoporous Pt nanorods using the assembly of surfactant micelles in confined space. Angew. Chem. Int. Ed. 52, 8050-8053 (2013).

34 Bates, F. S. \& Fredrickson, G. H. Block copolymer thermodynamics: theory and experiment. Annu. Rev. Phys. Chem. 41, 525-557 (1990).

35 Bates, F. S. \& Fredrickson, G. H. Block copolymers-designer soft materials. Phys. Today 52, 32-38 (1999).

36 Park, M., Harrison, C., Chaikin, P. M., Register, R. A. \& Adamson, D. H. Block copolymer lithography: periodic arrays of $\sim 10^{11}$ holes in 1 square centimeter. Science 276, 1401-1404 (1997).

37 Albrecht, T. T., Steiner, R., DeRouchey, J., Stafford, C. M., Huang, E., Bal, M., Tuominen, M., Hawker, C. J. \& Russell, T. P. Nanoscopic templates from oriented block copolymer films. Adv. Mater. 12, 787-791 (2000).

38 Cheng, J. Y., Ross, C. A., Chan, V. Z. H., Thomas, E. L., Lammertink, R. G. H. \& Vancso, G. J. Formation of a cobalt magnetic dot array via block copolymer lithography. Adv. Mater. 13, 1174-1178 (2001).

39 Zalusky, A. S., Valles, R. O., Taylor, C. J. \& Hillmyer, M. A. Mesoporous polystyrene monoliths. J. Am. Chem. Soc. 123, 1519-1520 (2001).

40 Tseng, W. H., Chen, C. K., Chiang, Y. W., Ho, R. M., Akasaka, S. \& Hasegawa, H. Helical nanocomposites from chiral block copolymer templates. J. Am. Chem. Soc 131, 1356-1357 (2009).

41 Tseng, Y. T., Tseng, W. H., Lin, C. H. \& Ho, R. M. Fabrication of double-length-scale patterns via lithography, block copolymer templating, and electrodeposition. Adv. Mater. 19, 3584-3588 (2007)

42 Hajduk, D. A., Harper, P. E., Gruner, S. M., Honeker, C. C., Kim, G., Thomas, E. L. \& Fetters, L. J. The gyroid: a new equilibrium morphology in weakly segregated diblock copolymers. Macromolecules 27, 4063-4075 (1994).

43 Schulz, M. F., Bates, F. S., Almdal, K. \& Mortensen, K. Epitaxial relationship for hexagonal-to-cubic phase transition in a book copolymer mixture. Phys. Rev. Lett. 73, 86-89 (1994).

44 Matsen, M. W. \& Schick, M. Stable and unstable phases of a diblock copolymer melt. Phys. Rev. Lett. 72, 2660-2663 (1994).
45 Takeji, H., Kiyoharu, T. \& Yoshinori, F. Nanoprocessing based on bicontinuous microdomains of block copolymers: nanochannels coated with metals. Langmuir 13 6869-6872 (1997).

46 Hsueh, H. Y., Huang, Y. C., Ho, R. M., Lai, C. H., Makida, T. \& Hasegawa, H. Nanoporous gyroid nickel from block copolymer templates via electroless plating. Adv. Mater. 23, 3041-3046 (2011).

47 Hsueh, H. Y., Chen, H. Y., Hung, Y. C., Ling, Y. C., Gwo, S. \& Ho, R. M. Well-defined multibranched gold with surface plasmon resonance in near-infrared region from seeding growth approach using gyroid block copolymer template. Adv. Mater. 25 1780-1786 (2013).

48 Crossland, E. J. W., Kamperman, M., Nedelcu, M., Ducati, C., Wiesner, U., Smilgies, D. M., Toombes, G. E. S., Hillmyer, M. A., Ludwigs, S., Steiner, U. \& Snaith, H. J. A bicontinuous double gyroid hybrid solar cell. Nano Lett. 9, 2807-2812 (2009).

49 Guldin, S., Rushkin, I., Stefik, M., Hur, K., Wiesner, U., Baumber, J. J. \& Steiner, U. Tunable mesoporous bragg reflectors based on block-copolymer self-assembly. Adv. Mater. 23, 3664-3668 (2011).

50 Scherer, M. R. J., Li, L., Cunha, P. M. S., Scherman, O. A. \& Steiner, U. Enhanced electrochromism in gyroid-structured vanadium pentoxide. Adv. Mater. 24, 1217-1221 (2012).

51 Hsueh, H. Y., Chen, H. Y., She, M. S., Chen, C. K., Ho, R. M., Gwo, S., Hasegawa, H. \& Thomas, E. L. Inorganic gyroid with exceptionally low refractive index from block copolymer templating. Nano Lett. 10, 4994-5000 (2010).

52 Hsueh, H. Y. \& Ho, R. M. Bicontinuous ceramics with high surface area from block copolymer templates. Langmuir 28, 8518-8529 (2012).

53 Jain, A., Toombes, G. E. S., Hall, L. M., Mahajan, S., Garcia, C. B. W., Probst, W., Gruner, S. M. \& Wiesner, U. Direct access to bicontinuous skeletal inorganic plumber's nightmare networks from block copolymers. Angew. Chem. Int. Ed. 4 1226-1229 (2005)

54 Finnefrock, A. C., Ulrich, R., Toombes, G. E. S., Gruner, S. M. \& Wiesner, U. The Plumber's nightmare: a new morphology in block copolymer-ceramic nanocomposites and mesoporous aluminosilicates. J. Am. Chem. Soc. 125, 13084-13093 (2003).

55 Chan, V. Z. H., Hoffman, J., Lee, V. Y., latro, H., Avgeropoulos, A., Hadjichristidis, N., Miller, R. D. \& Thomas, E. L. Ordered bicontinuous nanoporous and nanorelief ceramic films from self assembling polymer precursors. Science 286, 1716-1719 (1999).

56 Adachi, M., Okumura, A., Sivaniah, E. \& Hashimoto, T. Incorporation of metal nanoparticles into a double gyroid network texture. Macromolecules 39, 7352-7357 (2006).

57 Urade, V. N., Wei, T. C., Tate, M. P., Kowalski, J. D. \& Hillhouse, H. W. Nanofabrication of double-gyroid thin films. Chem. Mater. 19, 768-777 (2007).

58 Ho, R. M., Chen, C. K., Chiang, Y. W., Ko, B. T. \& Lin, C. C. Tubular nanostructures from degradable core-shell cylinder microstructures in chiral diblock copolymers. Adv. Mater. 18, 2355-2358 (2006).

59 Ho, R. M., Chiang, Y. W., Chen, C. K., Wang, H. W., Hasegawa, H., Akasaka, S. Thomas, E. L., Burger, C. \& Hsiao, B. S. Block copolymers with a twist. J. Am. Chem. Soc. 131, 18533-18542 (2009).

60 Chan, Y. N. C., Craig, G. S. W., Schrock, R. R. \& Cohenf, R. E. Synthesis of palladium and platinum nanoclusters within microphase-separated diblock copolymers. Chem. Mater 4, 885-894 (1992).

61 Li, C. \& Yamauchi, Y. Facile solution synthesis of Ag@Pt core-shell nanoparticles with dendritic Pt shells. Phys. Chem. Chem. Phys. 15, 3490-3496 (2013).

62 Cao, M., Wu, D., Gao, S. \& Cao, R. Platinum nanoparticles stabilized by cucurbit[6]uril with enhanced catalytic activity and excellent poisoning tolerance for methano electrooxidation. Chem. Eur. J 18, 12978-12985 (2012)

63 Iwasita, T. Electrocatalysis of methanol oxidation. Electrochimica Acta 47 3663-3674 (2002)

64 Russel, A. E. \& Rose, A. X-ray absorption spectroscopy of low temperature fuel cell catalysts. Chem. Rev. 104, 4613-4635 (2004).

(c) (i) This work is licensed under a Creative Commons Attribution 4.0 International License. The images or other third party material in this article are included in the article's Creative Commons license, unless indicated otherwise in the credit line; if the material is not included under the Creative Commons license, users will need to obtain permission from the license holder to reproduce the material. To view a copy of this license, visit http:// creativecommons.org/licenses/by/4.0/

Supplementary Information accompanies the paper on the NPG Asia Materials website (http://www.nature.com/am) 